\title{
DIÁLOGOS EM TORNO DOS SIGNIFICADOS DO CORPO NO ENVELHECIMENTO UM ESTUDO COM PESSOAS IDOSAS INSCRITAS NUM PROGRAMA DE ATIVIDADE FISICA
}

\author{
Carolina Torres ${ }^{1}$ \\ Paula Silva² \\ Carina Novais ${ }^{3}$ \\ Joana Carvalho ${ }^{4}$
}

1 Professora de Educação Física, licenciada em Desporto e Educação Física e mestre em Atividade Física para a Terceira Idade pela Faculdade de Desporto da Universidade do Porto. E-mail: carolina_fcdef@hotmail.com

2 Doutora em Ciências do Desporto pela Faculdade de Desporto da Universidade do Porto, onde exerce funções de docência e de investigação no Centro de Investigação em Atividade Física, Saúde e Lazer (CIAFEL). E-mail: psilva@fade.up.pt

3 Socióloga, investiga as questões de gênero e o envelhecimento; com uso de metodologias qualitativas, acede aos significados de atividade física para participantes em programas de AF para a terceira idade. E-mail: carinanovais@hotmail.com

4 Doutora em Ciências do Desporto pela Faculdade de Desporto da Universidade do Porto (FADEUP), onde exerce funções de docência e de investigação no Centro de Investigação em Atividade Física, Saúde e Lazer (CIAFEL). É presidente do Conselho Científico e diretora do curso de Mestrado em Atividade Física para a Terceira Idade. E-mail: jcarvalho@fade.up.pt 
resumo

presente estudo teve como principais objetivos identificar os motivos de adesão a um programa de atividade física (PAF) e analisar as perceções de idosos e idosas relativamente ao seu corpo durante o processo de envelhecimento, assim como a influência da prática de AF (atividade física) sobre a autopercepção corporal. Para tal, foram realizadas entrevistas semiestruturadas, posteriormente transcritas e formatadas para tratamento da informação no programa QSR NVivo 7. Após a categorização e tratamento dos dados, foi-nos possível concluir que a prática de atividade física desencadeou uma mudança positiva na forma como cada um vive e encara o seu corpo e o seu processo de envelhecimento, permitindo a estas pessoas a obtenção de uma nova atitude corporal que se refletiu ao nível pessoal, funcional e social.

palavras-chave

Corpo. Atividade Física. Envelhecimento.

\section{Introdução}

O envelhecimento é um processo natural e geneticamente programado, influenciado por diversos fatores relacionados com a genética, o meio ambiente, os estilos de vida, entre outros, sendo, por isso, individual e heterogêneo (FERNANDES et al., 2004; HASSE, 2006; SANTIAGO et al., 2009; SPIRDUSO et al., 2005). Sob o ponto de vista social, o envelhecimento é um processo marcado pela perda das relações sociais, em que se perde o espaço profissional e, consequentemente, o estatuto social proporcionado pela idade; perdem-se ainda os amigos por doença ou morte, o que promove o isolamento e a solidão (SANTIAGO et al., 2009). Estas perdas são também visíveis ao nível da autonomia corporal e psicológica, em que se perde a beleza física padronizada pela cultura atual, a saúde e a extensão infinita do futuro (GOLDFARB, 1997). Atualmente, sob o reinado do olhar, as informações que recolhemos provêm da aparência, tornando-se a superfície o lugar da profundidade (LE BRETON, 2004). Neste contexto, "o corpo ocupa um lugar muito alto na hierarquia axiológica dos tempos contemporâneos, [...] em que se apela a um modelo estético de corpo: alto, magro, jovem", sendo 
o nosso cartão de visita (LACERDA; QUEIRÓS, 2004, p. 2). Neste sentido, assistimos a uma era da corporeidade em que transpomos a realidade humana do ter corpo para o ser corpo (ESTEVES, 2005). A cultura inscreve-se no nosso corpo tornando-o um artifício, um projeto que reflete os valores da comunidade em que estamos inseridos (FERREIRA et al., 2008; JOHNSON, 1990; PALMEIRA, 2005) e que precisa ser trabalhado para estar na moda, ser controlado, ser normalizado e racionalizado (LIPOVETSKY, 1997), sendo visto como um lugar de autoidentidade (TWIGG, 2004). Neste contexto, existe uma vontade de domínio, um combate contra a lei heterônoma do tempo e do corpo (LIPOVETSKY, 1997), determinando "um desequilíbrio entre a idade biológica e a aparência física, de modo que envelhecer deixou de ser natural, tornou-se quase perverso" (LACERDA, 2007, p. 397), uma vez que há a exigência de envelhecer mantendo um aspecto jovem, belo e saudável. A pessoa idosa, ao apresentar um corpo que se afasta dos padrões dominantes na sociedade, é sujeita a alguns preconceitos e estereótipos negativos sobre o envelhecimento (JARDIM et al., 2007; FERNANDES, 2009; JUNIOR, 1997). A velhice é, por isso, considerada o momento mais dramático de mudança da imagem corporal, uma vez que é muito difícil aceitar esta imagem envelhecida numa sociedade que diviniza a beleza e a juventude (BLESSMAN, 2004). Na época da anti-idade e do anti-peso, existe uma crescente preocupação com as técnicas de prevenção e práticas de manutenção do corpo (LIPOVETSKY, 1997), recorre-se cada vez mais aos cuidados e tratamentos estéticos, às dietas e aos cuidados médicos, às operações plásticas e à prática de exercício físico para responder ao imperativo de se continuar eternamente jovem (BENTO, 2001). A literatura refere que a AF (atividade física) pode contribuir de uma forma positiva para melhorar a capacidade funcional, a saúde e a qualidade de vida das pessoas idosas (WHO, 1997), bem como para a manutenção de um corpo cuja morfologia respeite os padrões impostos socialmente (LACERDA, 2007, p. 398).

O envelhecimento apresenta interpretações sociais diferentes para a mulher e para o homem, existindo um duplo padrão baseado numa cronologia feminina e numa cronologia masculina culturalmente e socialmente definidas no contexto do capitalismo e do patriarcado (JUNIOR, 1997). Assim, o envelhecimento compromete a fonte tradicional de poder das mulheres que reside na aparência; já nos homens, em que se associa o poder ao dinheiro, ao estatuto, à dominação social, os sinais de envelhecimento tais como cabelos cinzentos são vistos como sinônimo de maturidade e autoridade (TWIGG, 2004). Os estereótipos relativos ao corpo envelhecido exercem um maior 
impacto sobre as mulheres relativamente aos homens (FERNANDES, 2009; KREKULA, 2007), o que pode ser justificado pelo fato de o corpo feminino ter sido mais sujeito ao controle imposto pela sociedade (FERNANDES, 2009; FOUCAULT, 1994; GOELLNER, 2003). O conceito gênero surge-nos então como uma categoria analítica importante, pois os corpos masculinos e femininos não têm sido percebidos e valorizados da mesma forma ao longo do tempo, parecendo existir uma tendência para hierarquizá-los (LOURO, 2003). Importa, por isso, referir que as idosas de hoje experimentaram por muito tempo relações de poder que definiram as noções sobre papéis femininos e masculinos, em que o homem possuía uma total autoridade sobre a mulher e os filhos, o que pode interferir na forma como a pessoa idosa percebe e encara o seu envelhecimento (FERNANDES, 2009). Também ao nível da prática de atividades físicas e desportivas, a literatura refere uma hegemonia masculina neste espaço, afastando as mulheres destas vivências (ROMERO, 2008). Atualmente, os corpos nas atividades físicas e desportivas admitem uma representação social saudável, de liberdade e de bem-estar, simbolizando um espaço de conciliação e de harmonia e de libertação do indivíduo do século XXI (SANTIAGO, 2008; LACERDA, 2007). Mas, apesar de estas atividades serem para todas as pessoas, facilmente verificamos que as idosas alegam estereótipos para não praticarem AF, pois ainda acreditam que é prejudicial e inapropriado serem fisicamente ativas por causa do declínio físico e da percepção de estarem muito velhas (AMARAL et al., 2007).

Tendo por base todo este quadro de referências, o presente estudo tem como principais objetivos identificar quais os motivos de adesão a um programa de AF (PAF) e analisar as perceções de idosos e idosas relativamente aos seus corpos durante o processo de envelhecimento, assim como a influência da prática de AF sobre a autopercepção corporal.

\section{Metodologia}

Foram realizadas entrevistas semiestruturadas a 30 pessoas (16 do sexo masculino e 14 do sexo feminino) com idades compreendidas entre os 56 e os 71 anos (idade média $=64 \pm 4$ ), que estavam a iniciar um PAF implementado por uma autarquia do distrito de Braga. As entrevistas foram realizadas pelo mesmo elemento da equipe de investigação após consentimento informado de todos/as os/as participantes. O guião das entrevistas contemplou, entre outros temas, questões relacionadas com as motivações para a inserção neste 
PAF e a percepção do corpo nas diversas fases da vida, incluindo no presente. As entrevistas gravadas em áudio foram integralmente transcritas e formatadas para tratamento da informação no programa QSR NVivo 7. Todos os nomes utilizados no texto são pseudônimos para assegurar o anonimato dos/as participantes.

\section{Análise e discussão dos resultados}

\subsection{Corpo testemunho do tempo vivido}

O corpo é testemunho do tempo (SANTIAGO, 2008), sendo o envelhecimento caracterizado como um processo que implica perdas das funções normais, diminuição da força e do vigor, da audição, da visão e da memória, e, ainda, da capacidade funcional, entre outras (TRINDADE, 2001). O discurso que vigora na maior parte das pessoas idosas entrevistadas sugere que as limitações surgidas com a idade trouxeram alguns dissabores, sendo responsáveis por um sentimento de insatisfação e de desencanto nesta etapa da vida. A perda da funcionalidade traduziu-se numa maior dificuldade na execução de tarefas aparentemente simples, tais como apanhar um objeto do chão e calçar os sapatos. Essa dificuldade apresentada em encarar o fato de atualmente já não conseguirem desempenhar tais tarefas com a mesma energia e o mesmo vigor que conseguiam antes, resulta, assim, num sentimento de incapacidade e inutilidade. Neste sentido, revelam uma insatisfação com as marcas impostas pelo envelhecimento, fazendo referência ao fato de como o corpo presente se distingue do corpo passado que recordam com nostalgia, pois ontem possuíam um corpo jovem e produtivo e hoje um corpo velho para viver numa sociedade orientada para o corpo jovem (SANTIAGO et al., 2009). Segundo Garcia (1999), estamos perante um duplo ser: aquilo que se é agora e aquilo que se foi outrora.

No dia a dia eu encontro-me sempre bastante triste [...], lembra-me o que era antigamente e o que sou hoje, muita diferença. (JAIME, 70 anos).

Ao que eu era e ao que eu estou agora! (CARLA, 70 anos).

No discurso dos homens, encontramos várias referências à perda da força física e das capacidades físicas para desempenharem determinados trabalhos, enquanto as mulheres expressam a sua preocupação por terem 
perdido genica para desempenharem as tarefas domésticas e o trabalho no campo. De fato, verificamos na literatura que os homens idosos são frequentemente desvalorizados porque são vistos com reduzida capacidade para o trabalho, enquanto as mulheres idosas são desvalorizadas quando são considerados os papéis sexuais e reprodutivos do passado, bem como os serviços domésticos prestados (JUNIOR, 1997). Desta forma, verificamos que as limitações impostas pelo tempo provocam sentimentos de insegurança e de falta de confiança bem como a criação de uma relação entre a doença e a velhice (LLANO et al., 2006). Neste sentido, com o envelhecimento, existe a tendência para a modificação da autoimagem, tornando-a menos positiva, o que contribui para uma diminuição da autoestima, pois autoimagem e autoestima estão interligadas, sendo dependentes uma da outra (MAZO, 2008).

Uma pessoa agora, está gasta, está..., enfim. Agora uma pessoa anda aqui assim, não se pode trabalhar: à uma, uma pessoa já tem os ossos todos gastos se trabalhou muito antigamente. Eu às vezes bem quero trabalhar, vou para o jardim, às vezes pego numa sachola dou duas escavadelas mas começa-me a doer as costas e eu arrumo a sachola. Fica que já trabalhaste muito, é esta vida. (MARIA, 68 anos).

Nos discursos dos homens, deparamo-nos com a problemática da nova condição de reformado, tendo esta sido encarada com bastante preocupação, uma vez que estavam habituados a serem mais ativos e a trabalharem fora de casa, pelo que atualmente se deparam com a dificuldade de ocuparem todo o tempo livre que possuem. Já os discursos das mulheres revelam o quanto é difícil verem-se "arrumadas a um canto", pois, tendo em conta a sociedade atual caracterizada pela produtividade, existe uma tendência para excluir as pessoas que não são mais produtivas, caracterizando-as erroneamente como sendo incapazes (TRINDADE, 2001), pelo que se torna mais difícil para estas mulheres aceitar todo este processo de envelhecimento. Assim, este sentimento de inutilidade criado pela sociedade e aceito por muitos idosos acaba por ser responsável por um sentimento de indiferença pela vida (FERREIRA, 2006) e de aproximação do fim da mesma, da morte que os espera a qualquer momento.

Pensei seriamente antes de me reformar. A minha maior dificuldade foi também a da minha mulher, e continua a ser, porque nós quando trabalhávamos não parávamos em casa; eu, era quase só para dormir e para comer e habituamo-nos a um sistema de vida que depois de reformado é totalmente diferente. (RUI, 64 anos).

No país em que estamos, nós chegarmos aos 60 anos e vermo-nos assim arrumadas a um canto é um bocado difícil. (VERA, 61 anos). 
No entanto, também verificamos que para algumas pessoas esta fase da vida continua a estar repleta de significados e representações positivas, em que o envelhecer é percebido como um privilégio e as marcas do tempo impressas no corpo como um motivo de orgulho, o que nos recorda que, de fato, o envelhecimento obedece a diferentes ritmos, sendo um processo individual (TRINDADE, 2001). Algumas pessoas conseguem, assim, combater a visão negativa que a sociedade constrói em volta do envelhecimento, desmistificando, desta forma, o estereótipo social criado em volta da imagem do indivíduo idoso. Sentem que ainda são capazes de fazer muitas coisas, e este sentimento de autonomia e de independência melhora a sua autoestima. Neste sentido, é importante afirmarmos que à medida que o tempo avança, apesar de surgirem limitações para o ser humano, ele não fica necessariamente parcial e/ou totalmente incapaz, pois continua estando apto para o cumprimento das ações quotidianas tanto pessoais quanto profissionais (ANTONELLI, 2007).

Eu encaro as coisas, a realidade, e isto é a realidade. Isto é a natureza. A gente vai andando e vai morrendo pouco a pouco porque toda a gente vai, e já tenho dito muitas vezes, feliz por chegar a esta idade e ter encorrilhas e cabelos brancos [...] são coisas que tenho muita honra. (PATRÍCIA, 68 anos).

Ora bem, eu estou bem. [...] mas agora, da maneira que estou e com a idade que tenho, ainda me sinto... ainda me sinto capaz de fazer muita coisa, não é? Gosto de fazer o meu trabalho, não gosto de me levantar tarde, gosto de me levantar cedo - de manhã é que começa o dia e não quero parar. Quero estar sempre a andar, para poder movimentar sempre. (MIGUEL, 68 anos).

Ficou ainda bem visível no discurso dos homens que ao longo das suas vidas houve uma redefinição do que é ser velho. Enquanto jovens entendiam que com 50 anos já seriam velhos, atualmente não é bem assim, pelo que a imagem que projetavam quando jovens acerca da velhice não corresponde à que possuem atualmente. Nesta perspectiva, o envelhecimento não é definido apenas pela passagem do tempo cronológico, apresentando o ser humano várias idades: a idade cronológica, a biológica, a social e a psicológica (TRINDADE, 2001).

Eu, quando era jovem, com 10 ou 8 anos, um adulto com a minha idade hoje, com 64 anos, já era velho. Uma pessoa morria, e quando se perguntava que idade é que tinha, se tinha 50 ou 55 anos já era velho, era isso que acontecia, que eu vivi na aldeia. As pessoas depois dos 50 anos [...] as pessoas já eram velhas e eu pensava nisso, quando tiver 50 anos já estou velhinho. E eu não estou, e tenho 64. [...] A sociedade evoluiu, a qualidade de vida melhorou, portanto tudo foi bom. (RUI, 64 anos). 


\subsection{Corpo(re)conquistado}

Do sentimento de nostalgia resultante da percepção de um corpo envelhecido, sofredor e desgastado pelo tempo, surge a necessidade de reconquistar/recuperar um corpo ativo, um corpo mais maleável, mais saudável. Neste contexto, a AF surge como um mecanismo de ajuda para superar as limitações impostas pelo tempo, sendo um meio para alcançar um corpo socialmente mais aceito. Foi possível constatarmos que os motivos referidos pelos/as entrevistados/as para a participação no PAF estão sobretudo relacionados com questões de saúde, de melhoria da condição física e funcionalidade. Afirmam que com a idade o corpo ficou mais preso, mais fraco e, por isso, começaram a ter mais limitações físicas e menos qualidade de vida. Os discursos refletem, ainda, a consciência de que a dor física que sentem é causada não só pelas marcas que o tempo deixou impressas nos seus corpos, mas também pela falta de AF. Vieram, por isso, praticar AF para o bem do corpo, para se movimentarem melhor e libertarem os "membros presos",

aproveitando a oportunidade de conseguirem um corpo mais ágil e com mais saúde. Revelam, assim, uma enorme consciência do valor da prática de AF para manterem a sua autonomia e a sua independência, o que coincide com o que a investigação tem revelado: (1) o avanço da idade e o "desuso" do corpo, ou seja, o sedentarismo, promovem um declínio da capacidade cardiovascular, da massa muscular, da força muscular, da flexibilidade e da capacidade funcional (OKUMA, 1998) e (2) um estilo de vida ativo pode ajudar a pessoa idosa a manter a sua funcionalidade e a sua autonomia, bem como a saúde e a qualidade de vida (SPIRDUSO et al., 2005).

Eu achei que era uma altura de cuidar um pouco, de ter um pouco de AF para manter aquela agilidade, não é, porque à medida que a idade avança vamos perdendo um pouco; o nosso organismo começa a ficar mais fraco e se não tivermos essa AF, o nosso corpo [...] vai ficando cada vez mais fraco, não é? (SIMÃO, 61 anos).

Eu tenho um problema de saúde. [...] Tive que me despachar e me desenrascar para fazer alguma atividade para o bem do meu corpo. Tenho necessidade de fazer isso, não posso estar sem fazer desporto, se não, um dia qualquer, fico para aí sentada numa cadeira. (ANDREIA, 64 anos).

A participação no PAF fez com que estes/as idosos/as apreciassem e desenvolvessem os seus níveis de $\mathrm{AF}$, considerando uma prioridade parti- 
cipar nas aulas do programa. É algo que, pelo impacto positivo percebido, passa a ser incluído nas suas rotinas, quase viciante, que os/as predispõe para serem mais ativos/as e os/as valoriza.

E isso passa a ser uma rotina e um hábito, é quase como um vício. (SIMÃO, 61 anos).

Eu acho que a ginástica que é assim, não sei explicar por que, mas sei que eu tenho outra atividade e tenho sempre vontade de me levantar de manhã seja a hora que for para vir [...] sinto-me mais aberta, com mais vontade de trabalhar. (BEATRIZ, 58 anos).

Os(as) entrevistados(as), de uma maneira geral, reconhecem a importância da prática de AF para a obtenção de um corpo mais saudável e mais funcional. Os seus discursos projetam um corpo ativo, mais ágil, com menos dores e que se mexe melhor, um corpo mais próximo do considerado ideal; sentem que estão melhores do que as pessoas que são sedentárias, o que reflete num aumento da qualidade de vida, da confiança e da autoestima. Apesar de a sociedade projetar a imagem da velhice como um corpo em decadência, sugerindo algo que não tem lugar (HASSE, 2006), os/as entrevistados/ as projetam um corpo ativo, que não se revê na referida imagem, referindo que com a prática de AF o corpo prisão deu lugar ao corpo liberto - liberto nos movimentos, liberto dos problemas, liberto de preconceitos, liberto para viver. Neste sentido, a independência funcional percecionada funciona como um adjuvante na obtenção de um lugar na estrutura social (GIDDENS, 2000). Uma melhor qualidade de vida parece, assim, estar garantida com a prática de $\mathrm{AF}$, na medida em que os/as entrevistados/as sentem-se mais jovens e mais confiantes com o seu corpo, com a certeza de que "se o corpo estiver são, também terão uma vida sã"; dessa forma, dá-se a eles a possibilidade de trilharem novos caminhos e de projetarem para o futuro novas ambições (RIBEIRO, 2004).

Acho que depois que comecei a fazer a ginástica que eu já melhorei. [...] eu nem me lembro que tenho problemas, sinto-me como quando tinha 30 ou 40 anos. (BEATRIZ, 58 anos).

Eu acho que estou muito bem para a idade que tenho. Olhando às vezes à minha volta, não se sabe o que o interior tem, mas sei que exteriormente, pelo menos, eu acho que estou normal. E melhor do que muitos que eu vejo que estão sempre parados e que não fazem rigorosamente nada. (DUARTE, 65 anos). 
Um corpo fisicamente mais ativo expande-se a outras dimensões, e as pessoas entrevistadas reencontraram um corpo socialmente ativo. As sessões do PAF surgiram como o lugar privilegiado de encontro, de interação com os outros, contribuindo para a oportunidade de reconstrução das redes sociais que ficaram mais frágeis com a saída do mercado de trabalho.

Eu gosto do convívio com os colegas que estão também na turma, somos conhecidos de há imensos anos e há sempre um convívio que é agradável e é bom porque já há muito tempo que não revia essas velhas amizades. (RENATO, 64 anos).

A gente conhece sempre pessoas, vai conhecendo outros colegas, vai conversando e pronto, é sempre bom. (EVA, 60 anos).

A prática de AF fomenta a integração e a participação social e cultural, promovendo a criação de novas amizades e o desempenho de novos papéis sociais, para além de também desenvolver a atividade social que pode substituir o trabalho, proporcionando sentimentos de satisfação e produtividade (LLANO et al., 2006; WHO, 1997). Em suma, a AF surge como um coadjuvante fundamental no processo de envelhecimento, não pela possibilidade de o evitar mas pela potencialidade desse processo natural ser atenuado nas suas diferentes dimensões (CARVALHO; MOTA, 2002).

\subsection{Dos sentidos do corpo ao corpo dos sentidos}

Os discursos dos entrevistados traduzem a consciência de que a imagem assume uma importância primordial em sermos ou não aceitos na sociedade. Refletem, por isso, uma enorme preocupação com a aparência, ambicionando um corpo apresentável que possa ser visto e aceito e, fundamentalmente, lutam para responder a essa exigência social atual do culto do corpo (GOELLNER, 2003). O corpo é, assim, alvo de uma preocupação constante, sendo uma fonte de inquietação e de insatisfação permanente, pois é através do corpo que vemos as marcas do tempo e, consequentemente, do envelhecimento. Os discursos revelam ainda a presença simbólica do "outro", refletem a importância de termos um corpo passível de ser apresentado ao "outro", sendo este encarado como aquele que observa e julga a nossa aparência. É então possível afirmarmos que "vivemos em relação", existimos, pelo corpo, em relação ao corpo do outro, e, desta forma, o corpo ganha formas 
modeladas pela sociedade (CAMINHA, 1997). Assistimos ainda a referências sobre os padrões de beleza de quando eram jovens, em que aos corpos magros associavam-se outros significados, de dificuldades econômicas, de fome, enquanto, atualmente, os padrões de beleza enaltecem o corpo magro. Neste sentido, podemos afirmar que o corpo é moldado socialmente, sendo "passível de distintos registros, dependentes da época [...] e da cultura a que pertença [...], considerado sede de construções e representações sociais do feminino e do masculino" (GOMES et al., 2008, p. 387).

Aceita-se mais depressa uma pessoa que seja simpática, que seja bonita, que tenha um corpo bonito. (PEDRO, 70 anos).

Porque a pessoa, basta que vai a andar, as pessoas olham para a pessoa, olha que jeitosa, que bonita e se for [feia] às vezes até viram as costas, já nem ligam tanto. (MARIA, 68 anos).

Naquela altura quem fosse muito magro era ou porque passava fome ou porque Ihe chamavam esqueleto, porque se usava a gordura [...]. Hoje em dia não [...] aquelas que no meu tempo me chamavam magricela queriam ter o meu corpo. (MANUELA, 61 anos).

É ainda notório, por parte dos homens, um desejo de terem um corpo que corresponda aos padrões contemporâneos, fazendo alusões ao corpo atlético, forte, magro, características estas que socialmente definem a imagem masculina. É patente a preocupação destes idosos pela reconquista de um corpo forte, com mais músculos, cientes que socialmente a força e o poder físico são associados à masculinidade dominante (SILVA et al., 2010).

Eu, realmente, tinha um pouco de orgulho no meu corpo. Tinha um corpo muito bem feito. Eu não tinha problemas em ir à praia e ficavam a olhar para mim porque eu era todo direitinho, não havia barriga, não havia nada, e eu quero voltar àqueles tempos antigos, manter aquele corpo esbelto, e eu orgulhava-me muito [...]. (SIMÃO, 61 anos).

[... um homem tem de cuidar do seu corpo para mostrar o seu ego, o seu físico, ter algum orgulho em si. (DUARTE, 65 anos).

Por outro lado, percebemos que as mulheres se preocupam fundamentalmente em ter um corpo magro e bonito para atraírem o sexo oposto; demonstram alguma preocupação com a eventualidade de o marido as trocar por estarem a envelhecer e a perder a sua aparência jovem. A busca e a preo- 
cupação relativamente à beleza são características centrais associadas ao feminino, sendo bem visível que as mulheres receiam perder valor social à medida que envelhecem, receiam a perda da capacidade para atrair o sexo oposto e são mais pressionadas do que os homens pelo estereótipo corporal (LACERDA, 2007; LOLAND, 2000; ROMERO, 1997).

Eu acho que a gente tem de andar sempre arranjadinha e limpinha porque senão, sabe como é, o marido ainda me troca. Para mim, o corpo tem muita importância para a mulher, claro. Temos de olhar um bocadinho pela boca para ter um corpo mais ou menos, não digo um corpo muito forte mas um corpo mais ou menos para a minha idade. (ELISABETE, 60 anos).

Verificamos ainda que nas referências dos idosos as alterações físicas estão muito presentes, fazem referência à barriga que aumentou, à barba que ficou branca, ao cabelo que caiu e à cara que também ficou mais envelhecida, no entanto todas estas alterações são bem aceitas.

Repare que a minha barba está praticamente toda branca, o cabelo ainda vai resistindo, mas a barba, praticamente tenho a barba toda branca. Mas pronto, não tenho problema absolutamente nenhum com isso. Nada, nada, nada! (RENATO, 64 anos).

Relativamente às mulheres verificamos que as opiniões se dividem. Algumas aceitam serenamente as alterações decorrentes do envelhecimento e encaram bem o seu corpo, enquanto outras têm mais dificuldade em aceitar estas alterações, direcionando os seus discursos para os aspectos que consideram negativos, como o aumento do peso.

Era jeitosa! Muito mais elegante, mais bonita, o corpo muito mais bonito, muito mais firme e tudo, e agora não. Agora a gente só vê banhas para um lado, e só vê banhas para o outro. É isto que a gente vê e, claro, que não tem comparação nenhuma com o corpo que tinha antigamente. (ANA, 66 anos).

Não sou daquelas pessoas que me intimido com aquilo que vejo ou com aquilo que tenho. Há pessoas: Ui Jesus por ter uma encorrilha! Isto é uma honra, a gente ter encorrilhas e ter o cabelo branco. (PATRÍCIA, 68 anos).

São ainda notórias referências à importância de se olharem ao espelho e gostarem da imagem refletida. $\mathrm{O}$ espelho oferece um meio primordial de acesso da pessoa à sua própria imagem e estabelece a ligação entre a pessoa e as expectativas sociais que se formam a partir da aparência do corpo (RUGGI; SILVA, 2011). 
Quando a gente olha para o espelho e gosta do nosso corpo, gosta da nossa cara, a gente tem sempre vaidade, tem sempre necessidade de mudar o visual ou o corte de cabelo. Eu sinto-me bem, olho para o espelho e ainda gosto de me ver. (RUI, 64 anos).

É através da imagem refletida do espelho que as pessoas têm consciência de como a sua aparência foi alterada pela passagem do tempo. À semelhança do espelho, também as fotografias transparecem as marcas do tempo, apresentando ao/à idoso/a uma imagem que, com frequência, não corresponde à idade sentida, ou, mais concretamente, um tempo cronológico que não corresponde a um tempo imaginário (CARDOSO, 2002). De fato, o espelho transmite-nos a diferença entre o corpo real e o corpo ideal que se traduz num "esboço visual de como o corpo precisa parecer (JOHNSON, 1990), o que frequentemente provoca um sentimento de angústia face a uma imagem corporal que é vista e sentida como estando distante dos padrões ideais impostos pela sociedade, estando isso também visível nos discursos dos entrevistados.

A gente vai para o espelho, quem eu era e quem eu sou. (ANA, 66 anos).

Atualmente, é assim, uma pessoa, às vezes ponho-me a pensar, meu Deus, já nem falando nas rugas nem nada, para ver preciso de óculos, já ouço um bocado mal, já, quer dizer, uma pessoa põe-se assim a pensar, mas depois, olhe, paciência, é a idade, é a idade, o corpo, olhe, paciência, também é assim, claro que uma pessoa nota uma diferença ao olhar para as fotografias, basta olhar para as fotografias, não é? (EVA, 60 anos).

\section{4 "Ser" corpo}

O corpo não é só o que temos mas também o que somos, e desempenha um papel importante na consciência do eu (BENTO, 2001; LACERDA; QUEIRÓS, 2004; HASSE, 2006). “O corpo é o local primeiro de identidade, o locus a partir do qual cada um diz do seu íntimo, da sua personalidade, das suas virtudes e defeitos" (GOELLNER, 2003, p. 39). Nos discursos analisados, é possível verificarmos uma dupla relação com o corpo, ou seja, uma distinção entre o "ser" corpo e o "ter corpo" (BENTO, 1995). Para alguns dos/ as entrevistados/as, o corpo é encarado como a prova primeira e única da sua identidade perante o outro, pois é através dele que a revelam enquanto homens ou mulheres. Por outro lado, encontramos discursos em que perce- 
bemos que o corpo assume uma dimensão mais global - "somos nós", "é a nossa vida" - e aqui o corpo aparece como o principal responsável pela nossa presença no mundo, dando sentido à nossa existência. $\mathrm{O}$ corpo pode então ser compreendido como algo que nós "temos" e algo que nós "somos" (KREKULA, 2007), e, apesar de, na maior parte das vezes, os entrevistados associarem as alterações do corpo a algo negativo, quando se referem ao corpo como a sua identidade, demonstram orgulho nos seus discursos.

O corpo é importante para mostrarmos aquilo que somos, que somos homens, não é? (DUARTE, 65 anos).

Eu acho que [o corpo] faz parte da feminilidade, da sexualidade, eu acho que sim, acho que nesse aspecto a pessoa tem de procurar ser mais atraente, é nesse sentido. (BEATRIZ, 58 anos).

Eu acho que sim, [o corpo é importante] é o nosso corpo, somos nós. É a nossa vida e nós viemos para o mundo foi para viver. A gente sem o corpo não andava cá, não vivia. E sou mulher com muito gosto, gosto de ser mulher, não me arrependo de como Deus me fez e me pôs no mundo, sou mulher e tenho muito gosto em ser mulher. (DULCE, 59 anos).

O corpo assume-se assim como "uma matéria à parte que revela um estado do sujeito, suporte de uma geometria variável de uma identidade escolhida e sempre revogável" (LE BRETON, 2004, p. 18).

\section{Considerações finais}

Os resultados deste estudo evidenciaram que os/as idosos/as vivem o processo de envelhecimento de forma heterogênea, existindo uma diferença na forma como cada um encara e perceciona o corpo envelhecido. Conseguimos ainda observar que as principais preocupações derivadas deste processo variam consoante o gênero. Assim, nos discursos do gênero masculino observamos uma preocupação com a perda da funcionalidade e da sua força, enquanto no gênero feminino são notórias as preocupações relativas à alteração da forma do corpo, nomeadamente no que concerne ao aumento do peso, bem como à perda da funcionalidade para realizar as tarefas domésticas. No entanto, todos expressam uma preocupação relativa à manutenção 
da sua autonomia que exerce uma enorme importância nesta fase das suas vidas. Os discursos dos/as entrevistados/as refletem ainda várias formas de ser e ter corpo, pelo que este pode ser entendido a partir de diferentes perspectivas.

Relativamente à $\mathrm{AF}$, verificamos que a sua prática foi encarada como um meio para superar as limitações impostas pelo passar do tempo, pelo que passou a ser uma rotina e uma prioridade nas suas vidas. Assim, foi possível verificarmos que os/as entrevistados/as reconhecem a importância da prática de AF para obterem um corpo mais saudável, mais funcional e esteticamente mais agradável, possibilitando-lhes a oportunidade de projetarem um novo corpo mais ágil, mais funcional e mais social. Acreditam que o fato de terem um estilo de vida mais saudável irá contribuir para terem uma melhor qualidade de vida, pelo que a prática de AF emerge como sendo um instrumento de concretização do corpo e da vida.

DIALOGUES AROUND THE MEANINGS

OF THE BODY AT AGING: A STUDY WITH OLDER PEOPLE ENGAGED IN A PROGRAM OF PHYSICAL ACTIVITY

\section{abstract}

The main purposes of this study were to identify the reasons for joining a Program of Physical Activity (PPA), analyzing the perceptions of older men and women in relation to their body during the aging process, as well as the influence of PA (physical activity) practice on this perception. For that, we conducted semi-structured interviews, which were then transcribed and formatted for data processing in the QSR NVivo 7 programme. After the categorization and treatment of the data, we were able to conclude that the practice of physical activity has triggered a positive change in how one lives and sees his/her body and its aging process, allowing these people to obtain a new bodily attitude which reflected on personal, functional and social levels.

keywords

Body. Physical Activity. Aging. 
AMARAL, Pamela et al. Atividades físicas no envelhecimento humano: uma leitura sensível criativa. Revista Brasileira de Ciências do Envelhecimento Humano, Passo Fundo, v. 4, n. 1, p. 18-27, jan./jun. 2007.

ANTONELLI, Paulo de. Representações da relação corpo/saúde em idosos praticantes de atividade física regular. 2007. 357 f. Tese (Doutorado em Ciências do Desporto e de Educação Física) - Faculdade de Ciências do Desporto e de Educação Física, Universidade do Porto, Porto, 2007.

BENTO, Jorge. O outro lado do desporto. Porto: Edições Campo de Letras, 1995.

Desporto, Corporalidade, Saúde, Vida. In: GUEDES, Onacir. Idoso, Esporte e Atividades Físicas. Brasil: Editora João Pessoa, 2001. p. 11-25.

BLESSMAN, Eliane. Corporeidade e envelhecimento: o significado do corpo na velhice. Estudos interdisciplinares sobre o envelhecimento, Porto Alegre, v. 6, n. 14, p. 21-39, 2004.

CAMINHA, Iraquitan. Mulher: "sua" corporeidade e "sua" sexualidade. In: ROMERO, Elaine. Mulheres em Movimento. Vitória: Editora Universidade Federal do Espírito Santo, 1997. p. 8-88.

CARDOSO, Maria. Representações de vida: um estudo realizado com adultos idosos. 2002. 220 f. Dissertação (Mestrado em Ciências do Desporto e de Educação Física) - Faculdade de Ciências do Desporto e de Educação Física, Universidade do Porto, Porto, 2002.

CARVALHO, Joana; MOTA, Jorge. A actividade física na terceira idade: justificação $e$ prática. Câmara Municipal de Oeiras: Divisão do Desporto, 2002.

ESTEVES, Diana. Sentido e significado de corpo, saúde e felicidade: um diálogo entre as teorias e a fala de idosos rurais e urbanos. 2005. 123 f. Dissertação (Mestrado em Ciências de Desporto e de Educação Física) - Faculdade de Ciências do Desporto e de Educação Física, Universidade do Porto, Porto, 2005.

FERNANDES, Ana et al. O sentido das idades da vida: interrogar a solidão e a dependência. 3. ed. Lisboa: CESDET Editores, 2004

FERNANDES, Maria. Problematizando o corpo e a sexualidade de mulheres idosas: o olhar de gênero e geração. Revista de enfermagem, Rio de Janeiro, v. 17, n. 3, p. 418-422, jul./set. 2009.

FERREIRA, Lucilene. A imagem refletida: olhares para o ser envelhecido em diferentes contextos sociais. 2006. 246 p. Dissertação (Pós-Graduação em Educação Física) Faculdade de Ciências da Saúde, Universidade Metodista de Piracicaba, Piracicaba, 2006.

FERREIRA, Maria et al. A busca frenética pelo corpo "ideal". In: ROMERO, Elaine. Universo do corpo: Masculinidades e feminilidades. Rio de Janeiro: Shape Editora, 2008. p. 305-330.

FOUCAULT, Michel. História da sexualidade Il: o uso dos prazeres. 8. ed. Lisboa: Edições Relógio d'Água, 1994.

GARCIA, Rui. Da Desportivização à Somatização da Sociedade. In: BENTO, Jorge. Contextos da Pedagogia do Desporto. Lisboa: Editora Livros Horizonte, 1999. p. 115-163. 
GIDDENS, Anthony. Dualidade da Estrutura: agência e estrutura. 3. ed. Oeiras: Edições Celta Editora, 2000

GOELLNER, Silvana. A produção cultural do corpo. In: LOURO, Guacira. Corpo, Gênero e Sexualidade: um debate contemporâneo na educação. Petrópolis: Vozes, 2003. p. 28-40

GOLDFARB, Delia. Corpo, tempo e envelhecimento. São Paulo: Edições Casa do Psicólogo, 1997.

GOMES, Paula et al. Distintos registros sobre o corpo feminino: beleza, desporto e mídia. In: ROMERO, Elaine. Universo do corpo: Masculinidades e feminilidades. Rio de Janeiro: Shape Editora, 2008. p. 387-399.

HASSE, Manuela. O corpo e o envelhecimento: imagens, conceitos e representações. In: BARREIROS, João. Atividade Física e Envelhecimento. Cruz Quebrada: Edições da Faculdade de Motricidade Humana, 2006. p. 17-27.

JARDIM, Viviane et al. Um olhar sobre o processo de envelhecimento: a percepção de idosos sobre a velhice. Revista brasileira de geriatria e gerontologia, Rio de Janeiro, v. 9, n. 2, p. 25-34, jan. 2007.

JOHNSON, Don. Corpo. 2. ed. Rio de Janeiro: Edições Nova Fronteira, 1990.

JUNIOR, Alfredo. A mulher idosa e as atividades físicas sob o enfoque multicultural. In: ROMERO, Elaine. Mulheres em Movimento. Vitória: Editora Universidade Federal do Espírito Santo, 1997. p. 81-88.

KREKULA, Clary. The intersection of age and gender: reworking gender theory and social gerontology. Current Sociology, London, v. 55, n. 2, p. 155-171, mar. 2007.

LACERDA, Teresa O. Uma aproximação estética ao corpo desportivo. Revista Portuguesa de Ciências do Desporto, Porto, v. 7, n. 3, p. 393-398, dez. 2007.

LACERDA, Teresa O.; QUEIRÓS, Paula. Desporto, corpo e estética - sinais de expressão da cultura contemporânea ocidental. In: CONGRESSO LUSO-AFRO-BRASILEIRO DE CIÊNCIAS SOCIAIS, 2004, 8., Coimbra. Anais... Coimbra: Centro de Estudos Sociais da Universidade de Coimbra, 2004. p. 1-8.

LE BRETON, David. Sinais de identidade: Tatuagens, piercings e outras marcas corporais. Lisboa: Edições Miosótis, 2004.

LIPOVETSKY, Gilles. A terceira mulher: Permanência e revolução do feminino. Lisboa: Edições Instituto Piaget, 1997.

LLANO, Mercedes et al. Guia prático de atividade física na terceira idade: envelhecer saudavelmente. 3. ed. Cacém: Edições Manz Produções, 2006.

LOLAND, Nina. The aging body: attitudes toward bodily appearance among physically active and inactive women and men of different ages. Journal of Aging and Physical Activity, Champaign, v. 8, n. 3, p. 197-213, July 2000.

LOURO, Guacira. Currículo, gênero e sexualidade - o "normal", o "diferente" e o "excêntrico". In: Corpo, gênero e sexualidade: um debate contemporâneo na educação. Petrópolis: Vozes, 2003. p. 41-52.

MAZO, Giovana. Atividade física, qualidade de vida e envelhecimento. Porto Alegre: Edições Sulina, 2008.

OKUMA, Silene. O idoso e a atividade física: fundamentos e pesquisa. 2. ed. Campinas: Papirus, 1998 
PALMEIRA, Tânia. O corpo na velhice: representações e práticas. 2005. 197 p. Tese (Mestrado em Sociologia) - Instituto de Ciências Sociais, Universidade do Minho, Braga, 2005.

RIBEIRO, Ana Maria. Representações do corpo nos idosos: um estudo centrado nas suas histórias de vida. 2004. 143 p. Dissertação (Mestrado em Ciências do Desporto e de Educação Física) - Faculdade de Ciências do Desporto e de Educação Física, Universidade do Porto, Porto, 2004.

ROMERO, Eliane. Construção e reprodução da masculinidade e da feminilidade no esporte pela mídia escrita. In: PEREIRA, Erik. Universo do corpo: Masculinidades e feminilidades. Rio de Janeiro: Shape Editora, 2008. p. 333-385.

ROMERO, Lahiry. Corpo, espelho da vida. In: ROMERO, Elaine. Mulheres em Movimento. Vitória: Editora Universidade Federal do Espirito Santo, 1997. p. 81-88.

RUGGI, Lennita O.; SILVA, Rosimeire B. O corpo no espelho: sobre a construção da feminilidade contemporânea. In: SEMINÁRIO NACIONAL GÉNERO E PRÁTICAS CULTURAIS, 2011, Coimbra. Anais... Coimbra: CESUC, 2011. p. 1-15

SANTIAGO, Leonea. Corpo, tempo e valores contemporâneos. In: ALBUQUERQUE, Alberto. Educação Física, Desporto e Lazer. Maia: Edições ISMAl, 2008. p. 201-208.

SANTIAGO, Leonea et al. Representações do corpo e saúde em idosos: aspectos sócio-antropológicos. In: XVI CONGRESSO BRASILEIRO DE CIÊNCIAS DO ESPORTE E III CONGRESSO INTERNACIONAL DE CIÊNCIAS DO ESPORTE, 2009, Salvador. Anais... Salvador: CBCE; CICE, 2009. p. 1-10.

SILVA, Paula et al. Construindo masculinidades: estudo das percepções em idosos do distrito do Porto. In: SEMINÁRIO INTERNACIONAL FAZENDO GËNERO, 9., 2010, Florianópolis. Anais eletrônicos... Florianópolis: NIPI, 2010. p. 1-9.

SPIRDUSO, Waineen et al. Physical Dimensions of aging. 2. ed. Champaign, Illinois: Edições Human Kinetics, 2005

TRINDADE, Maria. Envelhecimento e auto-estima. In: GUEDES, Onacir. Idoso, Esporte e Atividades Físicas. João Pessoa: Idéia, 2001. p. 11-25.

TWIGG, Julia. The body, gender, and age: feminist insights in social gerontology. Journal of aging studies, New York, v. 18, n. 1, p. 59-73, Feb. 2004.

WORLD HEALTH ORGANIZATION. The Heidelberg guidelines for promoting physical activity among older persons. Journal of Aging \& Physical Activity, Champaign, v. 5, n. 1, p. 2-8, Jan. 1997 